\title{
Medios e intolerancia social: La exclusión cotidiana
}

\author{
Gustavo Cimadevilla y Claudia Kenbel \\ (Universidad Nacional de Río Cuarto - Conicet)
}

Recibido: 16/12/2011

Aprobado: 24/1/2012

\begin{abstract}
Resumen: La falta de tolerancia, en las formas que se expresa mediáticamente como "discriminación", ocupa y preocupa a nuestras sociedades por sus implicancias disociativas. ¿Cuánto inciden los medios en provocarla o en contenerla? En ese sentido, y visto desde la academia, ¿qué formación estamos brindando y para qué medios y qué sociedad? Este trabajo intenta explorar una pequeña península de ese continente. El caso que nos interesa pone en escena a un medio radiofónico, a una red social y a la prensa local que registra una discriminación puesta en el "aire".
\end{abstract}

Palabras clave: discriminación / medios / formación comunicacional

\section{Media and social intolerance. The daily exclusion}

Summary: The lack of tolerance, in ways expressed in the media as "discrimination", is concerned about our society and their implications for dissociative meanings. How much influence the media has in provoking or containing this lack of tolerance? And in that sense and seen from the academy, what training are we providing and for what means and which society? This paper attempts to explore a small peninsula of the continent. The case in question enacts a radio medium, a social network and the local press start recording a discrimination in the "air".

Keywords: discrimination / media / communication training 


\section{Introducción}

C on media biblioteca cuestionándolos y la otra mitad tratando de destacar sus funcionalidades y potencialidades, los denominados "medios de comunicación tradicionales" -radio, televisión, prensa- y los nuevos medios electrónicos llaman la atención pública no solo por lo que ofrecen para el consumo del tiempo libre o la información orientadora, sino también por lo que protagonizan frente a determinados fenómenos sociales que conviene observar. La tolerancia -o mejor dicho la intolerancia- en las formas que se expresa mediáticamente como "discriminación" es el caso que nos ocupa para analizar su contemporaneidad.

¿Cuánto inciden los medios en provocarla o en contenerla?, ¿cuánto hacen por promover el cultivo de las mejores o peores costumbres de la civilidad? En ese sentido, y visto desde la academia, ¿qué formación estamos brindando y para qué medios y qué sociedad? Son preguntas que en muy pocos casos se pueden contestar.

No hay generalizaciones válidas, tampoco estudios abundantes y sostenidos, ni dificultades suficientes como para anular los ensayos interesados en analizar los protagonismos. Cada caso se traza sobre coordenadas específicas que se deben desentrañar. Los medios, como plural, dicen poco. Es cada medio y en situación el que dispara la correspondiente atención. Es cada medio, y por tanto sus coordenadas temporales y espaciales las que condicionan el análisis. Igual planteo podría sumarse al de las formaciones y el papel de la academia que refiere a realidades sumamente diversas.

Enfoques desde la ética, la política, la comunicología u otras del campo filosófico y social no cesan de abrir interrogantes y de procurar entendimientos porque lo que está en juego no se restringe a resolver cuestiones de conocimiento. Hay mucho más, son las propias posibilidades de vivir y convivir en democracia, con libertad y respeto y para construir juntos, lo que dispara la alarma y pone en discusión la cuestión.

Este trabajo intenta explorar una pequeña península de ese continente. El caso que nos interesa pone en escena a un medio radiofónico y su comunicador principal, a una red social que lo sigue, a la prensa local que eventualmente lo registra y a otros diversos actores que aunque no lo sepan se vuelven protagonistas.

El análisis, en esta instancia, no pretende partir de revisiones teóricas que incluyan a Locke y su Ensayo sobre la tolerancia (1666), ni a detenerse en los postulados de la Declaración Universal de los Derechos Humanos de la ONU (1948), sino simplemente rescatar el conjunto de los hechos conocidos, las participaciones manifiestas de los actores y las reflexiones que caben para quienes, actuando en el campo comunicacio- 
nal y académico, forman profesionales que con su conducta colocan en la agenda valores, promueven actitudes y colaboran en retratar la realidad social de este siglo. Reflexiones, también, para considerar cómo la investigación social desde las universidades puede aportar a la construcción de otros horizontes de comunidad donde la intolerancia ceda lugar al convivio.

Para ello, en un primer momento se esboza una síntesis de lo que se constituye en el caso de análisis propiamente dicho. En segundo término, se identifican las principales "partes" y las manifestaciones que emiten sus actores, así como algunos interrogantes comunicacionales necesarios para quienes se asumen como agentes de formación. En tercer lugar, el trabajo destaca algunas iniciativas que en el nivel de propuestas de investigación y socialización se han llevado a cabo sobre la problemática social en la que encuadra el caso. Se valora, en ese sentido, el aporte que pueden sumar ante la emergencia.

El trabajo, entonces, procura entrelazar la discusión sobre algunos de los flagelos contemporáneos de nuestras sociedades, cual es la intolerancia; los interrogantes que valen para nuestro campo cuando es la comunicación la que por su protagonismo llama la atención y el modo en que la academia puede generar respuestas que sumen para interactuar a tiempo ante problemáticas de exclusión.

\section{"Hay que matar a todos los negros de mierda..."}

El 11 de mayo del 2011, un joven locutor de la emisora de frecuencia modulada más antigua ${ }^{1}$ de la ciudad de Río Cuarto comenzó su programa ${ }^{2}$ diciendo que entendía a la gente que bregaba por tener armas para autodefenderse. Sin la habitual cortina musical de fondo, expresó que había sido víctima de un incidente y ello justificaba que su programa se constituyera en otro. Ya no eran la música estridente y la invitación a distenderse lo que caracterizaba a "su" espacio radial. El relato era otro y esa diferencia desataría luego varias derivas y debates necesarios.

1 Es la FM más antigua y un desprendimiento empresarial de la única AM local. La multiplicación de radios ocurrida a partir del surgimiento y expansión de las emisoras en frecuencia modulada, más otros factores producidos por transformaciones que se dieron tanto en el sistema de medios como en sus públicos, hicieron que ambas emisoras perdieran su centralidad en el marco de los medios locales, pero ambas siguen siendo reconocidas dentro de los medios más importantes de la ciudad y de la región (Grillo 2011: 4).

2 El programa se titula Pasajero nocturno y está dirigido principalmente al público juvenil, en una franja que va aproximadamente desde los 15 a los 35 años. En el 2011 cumplió diez años en el aire. 
Según versa la denuncia presentada contra el comunicador, ${ }^{3}$ este relató que cuando dejó el auto estacionado para dirigirse a la radio a hacer su programa, "dos negros de mierda que se conducían en un carro cartonero le tiraron con una naranja que le impactó en el pecho". Entonces calificó a los autores del incidente como "una lacra de la sociedad, que están en todo el país, habría que eliminarlos a todos por completo..." y luego de su explosiva desiderata una larga tanda musical se secuenció en el programa. Las expresiones, además, fueron publicadas en su página de Facebook Pasajero Nocturno -nombre del programa-, en la medida en que diversos participantes de la audiencia se manifestaron a favor o no del animador consternado.

En los hechos, por tanto, en fracción de minutos el "muro" digital del programa se llenó de comentarios alusivos y, en su mayoría, coincidiendo con los dichos del locutor. La atención a los comentarios registrados-gracias a la capturación de la página la misma noche que sucedió el evento- permite dimensionar el tono y los niveles de discriminación manifiestos: "No me pregunten por qué... no importa... me cagaron el día... Habría que matar a esos negros de mierda...", escribió el locutor entre los intercambios plasmados en el 'muro'.

Las adhesiones no fueron pocas: "son lacras... rateros de mierda que no dejan vivir en paz..."; o que están "para molestar". "iTe apoyo, odio a los negros de mierda, están para cagarle la vida a todos!", agregó uno de los oyentes internautas.

Así, varios de los "amigos" del programa en la red social Facebook hicieron alusión a experiencias propias para justificar sus dichos y línea de interpretación, como lo fue el caso de una joven que narró que cuando se habla de los "negros de mierda" "... se refiere a esos negritos de alma, resentidos y no al color de piel, a mí me quiso chorear un rubio ojos celestes!!! O sea... en fin, son una gran bosta!, el tema negros de mierda, de Los Chabelos, los describe tal cual... jaja!", agrega. Y una breve lectura sobre esa composición basta para comprender cómo se retrata al sector, y el estereotipo que se postula:

Todo el día con el tetra pa' bancar la vida, Musculosa vomitada con chorizo y birra La baranda que despiden siempre es mandarina

3 La denuncia fue presentada ante el fiscal de instrucción de la provincia, Julio Rivero, quien se apartó por entender que era competente para investigar el hecho el juez federal, por tratarse de un delito de su competencia. Hoy está radicada ante el Juzgado Federal de la ciudad de Río Cuarto. El doctor Sagarraga (denunciante) está a la espera de que el juez se avoque a entender en la investigación del delito y próximamente se constituirá en querellante principal de la causa. 
Es por eso que merecen que la gente diga

Negros de mierda

Parecen cucarachas que se amontonan en la basura,

Negros de mierda

No sirven para nada y van derecho hacia la fisura,

Negros de mierda

Hay que desinfectarlos pa' no mancharse con su negrura

Si tenés algún amigo demasiado oscuro

Olvidalo que es un negro se cae de maduro

Se te meten en tu casa y no vivís seguro

$Y$ si la ven a tu señora le tocan al culo

Negros de mierda

Habría que mandarlos a laburar a la cordillera,

Negros de mierda

Cada dos por tres se duermen la mona en una catrera,

Negros de mierda

Hay que esterilizarlos para que estén en franca extinción...

(y repite el texto completo)

Fuente: <http://www.musica.com/letras.asp?le tra $=1479013>;<$ http://www.youtube.com/wat $\mathrm{ch} ? \mathrm{v}=\mathrm{GyyKfdg} \times \mathrm{bBQ}>{ }^{4}$

El grupo musical que lo interpreta, Los Chabelos, está conformado por tres actores limeños. Hace casi dos años -relatan sus seguidoresGiovanni Ciccia, Sergio Galliani y Paul Vega, tres actores bastante conocidos en la capital peruana se juntaron simplemente para pasar el tiempo to- cando música, o mejor dicho para pasar el tiempo tocando... Dentro de los parámetros de Los Chabelos todo está permitido, comentan los sitios que los divulgan, como <http://www.lastfm. es/music/Chabelos>. Y en la web, así parece, también todo está permitido.

En esa línea, algunos otros 'feibuqueros' avanzaron un poco más y asociaron, de forma "casi natural", la pobreza y el clientelismo político a los subsidios y la vagancia.

Hablando desde el lugar de los "laburantes", otro oyente sostuvo que al final "[...] los derechos humanos son para los que roban o no trabajan. Para los pelo... [pelotudos] como nosotros no existe nada, solo trabajar y pagar impuestos para que le den a los que después te roban..." [refiriéndose a quienes reciben subsidios del estado por su condición de pobreza].

La agresión, supuestamente original, entonces, daba lugar a completar el estigma: no solo es un problema de condición: "negros de mierda" e inadaptación -agresores, vagos subsidiados sin justificación-; sino también de su marginalidad ante la ley: delincuentes.

Avivada luego la discusión, no tanto sobre el hecho en sí, porque el locutor no lo narró en el 'muro' del programa sino que lo relató al aire -en vivo-, hubo unas pocas intervenciones que

$4 \quad \mathrm{Al} 25$ de octubre del 2011 este video registra un ingreso de 1.133 .590 accesos. 
buscaron bajarle el tono a los dichos anteriores. Alegando que se trataba de comentarios "intolerantes" y "discriminatorios", expresaron, por ejemplo: "No me parece forma de tratar a la gente", "Qué fácil es repartir quién vive y quién muere. Hablan de matar gente!!!!!!!, de ser negros de mierda y tener armas para matarlos ya...".

$\mathrm{Al}$ respecto, el locutor remató con una frase que luego lo inculparía ante la Justicia: "Chicos, no empecemos con los comentarios que buscan justificar algunas conductas, ni con esas pelotudeces de los derechos humanos... ni comprensiones!!! Basta de que esa escoria nos joda la vida!!! BASTA... hay que eliminarlos a todos... por completo... a todos!!!".

Al cabo de unas pocas horas, todo el 'muro' del programa, con estos y otros comentarios del estilo, fue eliminado y se bloqueó su acceso "público".

\section{Una denuncia penal por "discriminación"}

Ocurrido el hecho, primero en el aire de la radio y al unísono en la red social de Facebook, vino el turno de la ciudadanía ante la justicia. El protagonista principal fue un abogado sensibilizado por la problemática que realizó una denuncia penal, argumentando que la conducta del locutor[...] encuadra en la figura delictiva del artículo $3^{\text {o }}$ de la Ley 23.592 sobre actos discriminatorios, que prevé la aplicación de una pena de 1 a 3 años de prisión para quienes por cualquier medio alentaren o incitaren a la persecución o el odio contra una persona o grupo de personas a causa de su raza, religión, nacionalidad o ideas políticas.

El texto de la denuncia fundamenta que "[...] quienes tienen la responsabilidad de estar al frente de programas de radio son formadores de opinión y deberían transmitir mensajes sin perjuicio de nada ni nadie". Según el letrado, del análisis de los dichos del locutor se desprende que este no solo incita a la violencia, sino que estructura "un discurso discriminatorio y racista, cargado de odio".

En ese marco, la denuncia destaca cómo el animador del programa "[...] legitima sus dichos en supuestos 'sentidos comunes' socialmente vigentes ('no empecemos con los comentarios que buscan justificar algunas conductas, ni con esas pelotudeces de los derechos humanos...')", sentencia el abogado.

La denuncia alude a la actual Ley de Servicios de Comunicación Audiovisual, ${ }^{5}$ que marca "[...] claros objetivos sobre los contenidos de los programas, los cuales deberían pro-

5 Ley 26.522, sancionada el 10 de octubre del 2009, durante el primer gobierno de la presidenta Cristina Fernández de Kirchner. 
pender al enriquecimiento cultural, a la elevación moral de la población, a la solidaridad social, al respeto de la libertad, de la dignidad de las personas y a los derechos humanos". Conceptos que, al entender del abogado, no fueron entendidos ni respetados por el locutor.

Y desde esa perspectiva, un capítulo insoslayable para considerar es el papel que cumple la Autoridad Federal de Servicios de Comunicación Audiovisual (Afsca), órgano de carácter nacional que -entre otras tareasse encarga de resaltar la composición de los contenidos que se emiten en la televisión abierta argentina desde: a) el origen de la producción; y b) el tipo de programas en el marco de la estructura de propiedad del sistema de medios. Y decimos insoslayable porque se constituye en un referente de la política pública. En este caso, preocupada por llevar adelante un Plan Nacional Contra la Discriminación que morigere ciertas tendencias que a su juicio se arraigan. A saber: i) la potenciación de las tradicionales formas de discriminación existentes en nuestra sociedad, ya que no es lo mismo ser mujer que mujer-pobre, migrante que migrante-pobre, indígena que indíge- na-pobre, negro que negro-pobre, discapacitado que discapacitado-pobre, viejo que viejo-pobre, etcétera); ii) la asociación estigmática entre racismo y pobreza, plasmada en las matrices configurativas del país: "indígenas", "cabecitas negras", "migrantes latinoamericanos" y otros que se ligaron a la pobreza cuando se estructuró el Estado nacional y las clases dominantes sesgaron la discriminación; y iii) finalmente, la propia criminalización de la pobreza (verificable en los índices de la población carcelaria y en ciertas prácticas de sospecha por "portación de cara", "color de piel" y "situación de marginalidad") (Afsca, en línea).

\section{Las repercusiones en la prensa local}

La presentación judicial tuvo su eco. El diario Puntal, ${ }^{6}$ principal periódico de la ciudad y pertenenciente a un grupo políticamente próximo al de la radio, lo destacó en sus páginas durante dos días consecutivos, a una semana de lo acontecido.

En la primera de las notas el diario encuadra la noticia a través de la denuncia penal mencionada anteriormente: "Por discriminación a cartone-

6 Puntal (Editorial Fundamento) es un periódico fundado en 1980 y tiene una distribución con alcance local y regional. Su línea editorial es próxima al Partido Radical y su orientación valora a la curia católica local. Es el principal órgano periodístico de la ciudad y suele marcar la agenda política del municipio y de la zona. Su dirección electrónica es <www. puntal.com.ar>. 
ros, denuncian a un locutor radial". Al día siguiente, cual derecho a réplica, el diario entrevista al conductor radial y la titulación es por demás expresiva: "Pido disculpas, fue la expresión de un momento de calentura". En la nota, el locutor admite que el episodio lo llevó a olvidarse de su rol de comunicador y terminó hablando como "un ciudadano común"; como si un ciudadano pudiese cultivar la intolerancia y promover la justicia propia y un comunicador no: "Lo dije como ciudadano, tal vez me olvidé del personaje que busca crear opinión a través de la radio. Sí, está bien, soy un comunicador y me equivoqué. Totalmente aceptado... totalmente aceptado. Pero la expresión fue de mucha bronca, de calentura por la inseguridad que tenés que vivir día tras día". Expresó el entrevistado del diario.

Y luego agrega: "Fue una expresión de bronca y en el momento en el que uno habla en caliente no se manejan algunos límites. Eso fue lo que me pasó, si tengo que pedir disculpas, les pido que por favor las acepten porque en ningún momento hubo discriminación o marginación, ni dije que habría que matar a los negros de mierda".

¿No dijo o no quiso decir?, podríamos agregar nosotros. $\mathrm{Y}$ sigue: “No tengo nada contra los negros, de hecho ahora ando vestido con una campera de Brasil y sabemos que originariamente fueron tierras ocupadas por esclavos negros", aseguró. En un impecable razonamiento -para él- acla- ratorio de su condición de no discriminador. En un impecable razonamiento sofista.

Cabe mencionar, y esto sí nos parece muy significativo, que la empresa radial no emitió ningún comunicado ni pronunciamiento institucional sobre lo sucedido. Ni otros medios se hicieron eco. Se sabe, sin embargo, que el comunicador fue "suspendido" en sus tareas por un periodo aproximado de un mes; lapso en el cual algunos de sus colegas mencionaron que el "Fabri", dado lo sucedido (sin más aclaraciones o eufemismos), "volverá a estar con nosotros en unas pocas semanas más"...

\section{Algunas reflexiones desde la formación: Comunicando desde una posición comprometida}

¿Es la formación profesional una condición que colabora para disminuir los prejuicios sociales en los contenidos mediáticos, en las generalizaciones infundadas de cronistas y editorialistas y en las apologías irresponsables de ciertos animadores que pueden justificar el armarse y matar para eliminar a los "incivilizados"?

Los niveles de profesionalización en el sector de las "industrias culturales" de América Latina se han elevado sustancialmente desde que la educación universitaria y terciaria han ampliado significativamente su oferta educativa y desde que en algunos paí- 
ses las legislaciones favorecieron las incorporaciones de profesionales en el área. Unas breves consideraciones permiten argumentar positivamente el papel de la formación superior para cultivar en profesionales conductas deseables y adecuadas del comunicar. ${ }^{7}$ Formación que en este caso el protagonista radial no tiene. En ese sentido, al menos tres áreas de conocimiento colaboran sustantivamente: el de las teorías comunicacionales y sociales (explicativas), el de la ética y el derecho (normativas) y el de la historia y las prácticas (comprensivas).

Veamos a qué nos referimos:

a) Teorías sobre la comunicación.Orientadoras principales del campo, las teorías y sistematizaciones diversas que ofrecen marcos desde los cuales observar, seleccionar, comprender y problematizar aspectos de las realidades sociales en las que convergen procesos de interacción y producción de significados, mediatizaciones y configuraciones socioculturales múltiples, son herramientas claves para dimensio- nar las complejidades sociales en las que se constituye cualquier objeto de interrogación comunicacional. El mundo y sus actores se dejan de explicar "hipodérmicamente" 8 cuando el conocimiento que viene sistematizándose desde la década de 1930 es la base y referencia para la argumentación. Con lecturas diversas, con posiciones teóricas no siempre conciliables, pero con la certeza de que lo que se busca explicar no admite simplicidades ni ingenuidades -de valor, de ética y de posición-, el conjunto de teorías disponibles abren siempre posibilidades para los análisis multivariados atentos a los diálogos disciplinares. Claro que ninguna teoría de la comunicación debería cultivarse sin dar cuenta de su contexto de origen, del paradigma al que remiten sus supuestos principales, así como de la manera en que sus autores llegaron a elaborar los planteos teóricos propuestos. Algunos ejemplos para ilustrar este aspecto los constituyen los textos que recuperan las

7 Si establecemos una analogía sobre la tarea de comunicar con el pensamiento de Antonio Gramsci acerca de los intelectuales (todos somos intelectuales), diríamos que "todos somos comunicadores", pero solo algunos ejercen la función social de comunicar. De igual manera, Gramsci sostuvo que "todos los hombres son intelectuales; pero no todos los hombres tienen en la sociedad la función de intelectuales" (Gramsci 2000), aludiendo a que cuando se refiere a los intelectuales está refiriéndose a la actividad profesional específica. Actividad, por tanto, que requiere de cierto esfuerzo de formación y determinadas responsabilidades conexas.

8 Con razonamientos que vinculan estímulos $\mathrm{X}$ a respuestas $\mathrm{Y}$. Véase, por ejemplo, a $\mathrm{M}$. Wolf (1987). 
trayectorias de las teorías sobre la comunicación. Podemos mencionar los balances sobre los estudios de comunicación latinoamericanos realizados por autores como Jesús Martín Barbero, Héctor Schmucler, Sergio Caletti, Alicia Entel, María Cristina Mata, Guillermo Orozco Gómez o Vassalo de Lopes y Fuentes Navarro; Quienes se refieren a las "macrotendencias", las "perspectivas" o "los temas de la agenda" en relación al estudio de la comunicación. ${ }^{9}$

La experiencia como docentes, en tanto, nos indica que las teorías se comprenden mejor cuando los estudiantes cuentan con los elementos suficientes como para poner en contexto tales desarrollos. Por ejemplo, con relación a cuáles fueron las preocupaciones al momento de ser producidas ("clima de época"), así como en qué país o región nacieron y se desarrollaron (no es lo mismo el contexto de surgimiento de la teoría de la "persuasión" que la de los "estudios culturales británicos", por caso), hasta incluso el "momento" en la vida del intelectual (o del grupo) que las produjo.
En esa línea no está de más aclarar que existen vínculos concretos entre la afinidad que un profesional tiene respecto de una propuesta teórica -consciente o no- y sus concepciones y decisiones profesionales consecuentes. Ello desde lo más elemental (la forma en que concibe la comunicación: proceso, intercambio, difusión, etcétera; o concibe a su público: acrítico o con capacidad de decodificación) a lo más sofisticado y sus intermedios, como puede serlo el entendimiento sobre la naturaleza del proceso de circulación de mensajes y la construcción de sentidos. Así, si bien el conocimiento de las herramientas teóricas no garantiza que el formado esté exento de caer en prácticas intolerantes o discriminatorias, sí puede presumir que está dotado de criterios que le permiten valorar mejor lo que resulta de su propia actuación profesional toda vez que conoce el contexto y procesos en los que se inserta. Pero las teorías comunicacionales tienen su base en las teorías sociales. Veamos.

b) Teorías sociales.- Punto de partida para el desarrollo inicial y constante del campo comunicacional,

9 Por citar alguno, vale el texto que compilan I. Vassallo de Lopes y R. Fuentes Navarro: Comunicación. Campo y objeto de estudio (2005). Una deuda pendiente, en este sentido, se mantiene por el reducido número de textos que se ocupen de efectuar balances críticos sobre estudios y teorías de la comunicación que trasciendan el ámbito mediático. Por ejemplo, atentos a los vínculos entre comunicación y organizaciones sociales o comunicación y problemáticas ciudadanas, entre otras. 
el acervo de conocimiento de la sociología, psicología social, antropología, economía y política, entre las principales, permitió sostener los razonamientos sustanciales que estructuraron los distintos paradigmas. Pensar la comunicación desde las teorías sociales es pensar la comunicación desde su propio andamiaje, pues ha sido el cultivo interdisciplinario de aquellas las que permitieron su nacimiento, crecimiento y complejización. Son entonces las teorías sociales punto de partida pero también de tránsito para comprender las dinámicas sociales y políticas y situar los fenómenos comunicacionales por extenso.

Categorías como las de cultura, tiempo, espacio, ciudad, interculturalidad, poder, globalización, subjetividad, por mencionar algunas, serían impensables sin los aportes de las ciencias sociales mencionadas. Como tampoco pueden omitirse los aportes -en materia de metodología para el abordaje de los fenómenos sociales- que las técnicas para el análisis del discurso, las etnografías, los grupos de discusión o las diversas propuestas para la recolección y el registro de datos primarios ofrecen.

Martín Barbero (1997: 56) nos recuerda que ciertas asignaturas 'matrices' no pueden faltar en el 'pensum' de comunicación: historia, teoría del conocimiento, filosofía, antropología, economía o sociología son claves. Y ejemplifica: "trabajar en un periódico no es simplemente escribir bien". Todo relato o texto incluye posiciones sobre las cuales pesan "intereses contradictorios" (Martín Barbero 1997: 57). La formación en teoría social, por tanto, contribuye a crear en quien se forma una "conciencia crítica", lo que se traduciría en el ejercicio de la profesión en términos de una plena conciencia respecto de los contenidos y valores que se ponen a circular.

En el caso que nos ocupa queda claro que esa "conciencia" respecto de las implicaciones que tienen la justificación de la violencia o el cultivo de prejuicios discriminatorios a través de medios (la radio, pero también la red social) está totalmente ausente, incluso como instancia posterior, pues quien las protagoniza no advierte la naturaleza del error, ni siquiera cuando lo reflexiona: su problema no era discriminar o alentar la violencia, su problema era ejercerla en tanto comunicador.

c) Ética y derecho.- En el campo normativo, en tanto, la dimensión ética de lo social remite al valor de la "convivencia, a los modos de interacción de los seres humanos" y a la "reflexión crítica sobre un estado de cosas dado" (Heler 2004: 113). En ese marco, la ética es indisociable de toda profesión que, como la del comunicador, se ejerce mediante la construcción de lazos y relatos que 
colaboran a formar las imágenes de la realidad que se vive; pone a circular parámetros para la aceptación y el rechazo de las ideas y de los constructos materiales y simbólicos; y promueve la atención de determinados hechos en detrimento de otros. El derecho, luego, será la carga efectiva en donde lo habilitado o no, lo plausible o no, resguarda esa convivencia que importa a la ética y sin la cual no habría sociedad posible. Si la ética y el derecho no son patrimonio de unos sino de todos (en tanto surge en un estado de derecho de construcciones colectivas), se corporiza con mayor responsabilidad para quienes tienen la condición privilegiada de hacer pública su voz y pensamiento. Formarse en ética y formarse en derecho, al menos en aquello que resulta elemental ${ }^{10}$ para ser cons- ciente de las responsabilidades que se ejercen, será medida del valor que el comunicador le atribuye a esa condición; pero también medida del valor que le asignan la academia y lo gremial respecto de su papel para el ejercicio profesional. Será medida, también, del valor que empresarios y políticos le asignan a esa propiedad que se revela en los ejercicios de la comunicación. Temáticas que desde la academia se vinculan a asignaturas como Legislación sobre Medios de Comunicación, Economía Política de la Comunicación, Políticas Públicas sobre Comunicación y Cultura", entre otras (Cátedra Unesco 2008).

d) Historia y reconocimiento de las prácticas.- Agrega a la comprensión de cada caso el contexto necesario para que las lecturas se correspondan. El devenir de los denominados

10 En Argentina la sanción de la Ley 26.522 (2009), denominada la “Ley de medios”, reavivó el debate sobre el rol del Estado en la regulación de "instancias destinadas a las condiciones de los medios en tanto emisores últimos frente al público". Pero también de "[...] otras circunstancias de orden de políticas públicas regulatorias y de promoción del derecho a la información y al aprovechamiento y alfabetización tecnológica superando los criterios basados en la sola previsión del soporte técnico". La ley entiende que el rol de los medios de comunicación radica en promover la "[...] diversidad y la universalidad en el acceso y la participación, implicando ello igualdad de oportunidades de todos los habitantes de la Nación para acceder a los beneficios de su prestación. En particular, importa la satisfacción de las necesidades de información y comunicación social de las comunidades en que los medios estén instalados y alcanzan en su área de cobertura o prestación". De este modo, la legislación exige su apropiación por parte de todos los sectores sociales para el logro de su paulatina implementación. Contempla, para ello, la organización de la ciudadanía para participar de la "Defensoría del público", así como la adjudicación de licencias para actores antes no contemplados en las legislaciones anteriores, como las universidades, las organizaciones sociales, los cultos y el sector cooperativo (Afsca, en línea). 
"medios de comunicación" colectiva; la trayectoria de los profesionales de la comunicación; los rasgos de mayor o menor tolerancia de las comunidades donde actúan; las sucesivas políticas para contemplar esas esferas de la sociedad involucran conocimientos que permiten calibrar adecuadamente las posturas y situarlas correctamente en sus coordenadas. Al respecto, un pasaje interesante de una entrevista realizada a Jesús Martín Barbero para el número 31 de la revista Signo y Pensamiento, titulada justamente "Profesiones en juego", dice:

Yo escribí alguna vez que si el comunicador no es capaz de poner su voz al servicio de las demandas colectivas es un tipo que está robándole a la gente un derecho primario. Porque la gente sabe hablar, sabe escribir y dibujar, y entonces resulta que cuando un señor se apropia de ese saber, lo que está haciendo es expropiando a la gente un derecho fundamental que es el de hacerse oír y expresarse (1997: 57).

Desde nuestras prácticas en la docencia y la investigación advertimos la importancia del ejercicio de los procesos de aprendizaje fuera de las aulas: donde el laboratorio es la propia realidad. Donde los problemas reales pasan por las organizaciones y sus dificultades para identificar sus debilidades y buscar soluciones creativas y a su medida; o a las dificultades para reconocer canales o valorar también a la producción colectiva de los conocimientos que les resultan necesarios para consolidar los procesos de construcción de sujetos sociales (Abatedaga 2008). ${ }^{11}$

Es decir, el contacto con los problemas reales, con la diversidad de situaciones problemáticas, intereses

11 Una línea interesante de trabajo en la Universidad Nacional de Río Cuarto son las llamadas "prácticas sociocomunitarias". Esta supone incorporar a todas las carreras la realización de prácticas de aprendizaje y servicio solidario en la comunidad. Algunos ejemplos son los proyectos de extensión universitaria, los de responsabilidad social universitaria, voluntariado, prácticas profesionales, etcétera, que se encuentren articulados intencionadamente con contenidos académicos y de formación de competencias profesionales y para la ciudadanía (contenidos curriculares, reflexión, desarrollo de competencias para la ciudadanía y el trabajo, investigación). Véanse, al respecto, los enfoques del Centro Latinoamericano de Aprendizaje y Servicios Solidarios (CLAYSS), en <http://www.clayss. org.ar/>. En ese enfoque la comunidad ya no es vista ni como "destinataria pasiva" ni como "cliente", sino como un "espacio donde se aprende, se investiga, se construyen alianzas institucionales y donde las iniciativas solidarias llevadas a cabo junto con la comunidad son para los estudiantes y los docentes una forma de aprender y de investigar. Por supuesto que propuestas de estas características exigen reacomodamientos importantes por parte de las instituciones de formación, flexibilidad en sus currículos y renovadas formas de entender la producción de conocimiento. 
cruzados y alternativas de solución facilita en la formación de los profesionales instancias que no suplantan a los aprendizajes de la teoría, sino que en todo caso los complementan, les permiten dialogar y transitar entre lo abstracto y lo concreto para que las capacidades críticas resulten una consecuencia de ese hacer y reflexionar situado.

En síntesis, si el campo académico de la comunicación es, en comparación con el de la historia, la psicología o la sociología, aún más "joven" (Wallerstein 2003), no por ello resulta imberbe o imposibilitado de generar formaciones maduras. Justamente su carácter interdisciplinario -que asume el diálogo entre saberes- colabora con ofrecer perfiles de profesionalización amplios y el cultivo de un tipo de conocimiento "capaz de hacerse cargo de la multidimensionalidad de los problemas de la sociedad y de empezar a pensar desde el mundo" (Martín Barbero 2005: 69). Y ejercicios de ese tipo, antes que discriminar, integran. Suman y articulan.

\section{Algunas reflexiones desde la investigación: Conocer y compartir por una academia comprometida}

Un último aspecto que abordamos en este intento por entrelazar la dis- cusión sobre algunos de los flagelos contemporáneos de nuestras sociedades es el de la intolerancia. Los interrogantes que valen para nuestro campo cuando es la comunicación la que por su protagonismo llama la atención, y el modo en que la academia puede generar respuestas que sumen para interactuar a tiempo ante problemáticas de exclusión son los aporte que la investigación y la extensión pueden brindar desde las universidades.

En ese marco, nuestro trabajo dentro de una línea de interrogación que denominamos "Comunicación y rurbanidad" ha podido ofrecer ciertos desarrollos. Entre ellos mencionaremos algunos en el nivel de conocimiento y otros en el nivel de intervención.

"Comunicación y Rurbanidad" expresa una línea temática y problemática que empieza a configurarse cuando el foco de atención en nuestra región (centro de Argentina) se orienta a analizar algunas transformaciones que se advierten en el nivel de "emergencias" (Cimadevilla 2010). Esto es, en el nivel de fenómenos regionales en constitución y con derivas en las problemáticas sociales del territorio. Entre ellas, dos desplazamientos que plantean cierta desatención de lo rural en beneficio de lo agropecuario y cierta invisibilización de un tipo de actores: los rurbanos. $^{12}$

12 Ni urbanos ni rurales, los actores rurbanos presentan cierta síntesis que resulta de su residir en ciudades pero cultivar prácticas, aprovechar saberes y sostener concepciones más próximas a lo rural (Cimadevilla y Carniglia 2009). 
Así, el primer desplazamiento al que nos referimos es el de la sustitución de lo rural por lo agropecuario. Esto es, y en su consecuencia, el ya no pensar en lo rural como ambiente y hábitat, condición sociocultural, forma de vida y cuadro relacional sino estrictamente en cuanto sistema productivo, capacidad de producción y potencialidad económica que se resume en un concepto: el de agropecuario. Así, lo agropecuario remite cada vez más a las estrategias frente a la estacionalidad, los paquetes tecnológicos y los planes de mercado a futuro; y mucho, mucho menos, a "la tenaza y el atado con alambre",;3 o a cualquier otra postal costumbrista en la que se sitúa su gente y su cotidianidad.

La operación no es menor. Si lo rural deja de vincularse al modo en cómo la gente vive, se constituye y desenvuelve en un territorio que por cierto responde a ciertas características que lo definen; si lo rural pasa entonces solo a verse como el lugar en el que se dan cierto tipos de producciones y negocios, la gente, su condición y su cultura, se invisibilizan y priman las medidas de tonelaje, los rindes y la productividad y las proyecciones de volúmenes de producción. La mercadería y los mercaderes, entonces, cubren el paisaje que no tiene otra vida que la que cotiza en bolsa.
En otro sentido se da un segundo desplazamiento que tampoco es menor y tiene correlatos extensivos. Se trata de otra operación de sustitución, en este caso de la "ciudad mercado" que reemplaza a la ciudad como lugar de "hábitat". El de la ciudad como lugar de transacciones antes que residencia, encuentro y agregación. El de la ciudad para comerciar, antes que para reunirse, hablar y compartir. Así, la urbe que se concibió en nuestras coordenadas geográficas plantando primero la plaza, las instituciones (el cabildo o municipio, la policía y la iglesia) y las viviendas, va cediendo esos espacios a los bancos, los complejos comerciales y las casas de cambio (Romero 2009). Sus habitantes, en consecuencia, según su condición de clase pueden elegir o no dónde residir; y cuando tienen la opción, cambian sus espacios por otros, paradójicamente más aislados. La ciudad, entonces, ya no reúne para convivir, en todo caso reúne para comerciar o negociar. El "Señor y su familia" ya no viven frente a la plaza, sino que viven en el country.

Es en esa ciudad que otro fenómeno emergente se vuelve visible a veces e invisible otras. Se trata de los actores rurbanos, cartoneros, recicladores de materiales, transportistas de áridos que con sus carros y caballos aparecen en los medios para dar cuenta de su

13 Expresión que se utiliza para graficar el estilo a través del cual con escasos elementos los residentes del interior intentan resolver sus problemas y circunstancias. 
carácter problemático en torno a la pobreza, los inconvenientes en el tránsito, los problemas ambientales, etcétera, en un entorno de "inadecuaciones" y alguna denuncia como la postulada por nuestro "protagonista radial". Y a ese conjunto de argumentos hay que añadirle una preocupación latente. Aquella que refiere al carácter "moderno" del espacio citadino, a los contrastes y a los significados que estos actores, sus dispositivos y prácticas rurbanas conllevan y las distancias que manifiestan entre la urbe que se imagina "apuesta al futuro" y la urbe que se "contamina" de esas otras postales "pretéritas".

En este sentido, las lecturas mediáticas sobre la rurbanidad pocas veces propician una reflexión que trascienda la situación coyuntural, desconocen el carácter rural de la experiencia de vida rurbana y propician una mirada unidimensional y "estigmatizante" de esta. Las coberturas, en última instancia, dan cuenta de grandes estereotipos que no permiten acceder a la complejidad de esa condición de vida. Aproximarnos a la ciudad narrada desde los medios supone acercarnos a un discurso que clasifica, ordena, opone, distribuye los elementos de la realidad y transforma en "orden" el desorden del mundo, según afirma Martín Barbero (1987), sin matices ni explicaciones.

Esas preocupaciones resultan consonantes a los desplazamientos apuntados. Si lo rural deviene en "agropecuario" y la urbe pasa a ser "ciudad mercado", el esquema de valor dominante frente a los objetos rurbanos es el que fija el sistema de intercambio de mercaderías y las expectativas de una sociedad de la producción y el consumo. Para ese régimen los objetos de naturaleza y utilidad diferentes tienen su legitimidad en tanto puedan expresarse en moneda de cambio; predomina así lo cuantitativo y lo abstracto por sobre lo cualitativo y lo concreto, impera una igualdad abstracta y se suprime lo diferente: todo debe ser homogéneo porque todo es igualable y susceptible de ser valorado en términos de dinero. ¿Qué vale en ese marco un carro artesanal y un caballo de tiro? ${ }^{14}$ ¿Qué vale una actividad de rebusque que aspira a la sobrevivencia? ¿Por qué, entonces, a estos protagonistas que delinquen hay que justificarlos? Diría quizás el protagonista radial que inició este diálogo.

El conocimiento que se ha aportado en estos años, entonces, procuró desentrañar las prácticas, comprender los

14 Lejos de ser una mera herramienta laboral, carro y caballo se emplean en una multiplicidad de actividades sociales, recreativas y lúdicas; se inscriben en una compleja trama simbólica que entre mezcla necesidad, gusto y placer e inauguran un vínculo que excede lo instrumental y se reconfigura a partir del afecto y el apego (Cimadevilla, Demarchi y Galimberti 2010). 
ambientes, poner en significación su sistema de objetos, reconocer sus valores, analizar el cuadro de sus interacciones y por sobre todo hacer visible su entramado de inclusiones y exclusiones y el modo en que la tolerancia pública -de políticas, de sentidos de aceptación dominantes, de relatos que los retratan- se manifiesta y ha manifestado.

Pero el conocimiento poco aporta si no consigue compartirse y circular. Con esa consigna algunas intervenciones han logrado poner en la agenda local el nivel de preocupación planteado.

- La producción de un material audiovisual para fines educativos distribuido en todas las escuelas medias y primarias de la localidad (Carreros. Relatos desde el rebusque, 2010. <http://www.youtube.com/ watch?v=yNSYd6hLZC $8>)^{15}$ fue reconocido por el municipio, premiado y posteriormente apoyado a nivel provincial para multiplicar a su divulgación en el sistema educativo.

- La participación en la ciudad en una audiencia pública destinada a discutir la política ambiental y la recolección de residuos; así como el apoyo institucional a la consolidación de una agrupación solidaria del sector (Cooperativa de Trabajo "Todo Sirve" Limitada) fueron otras acciones que colaboraron a sostener en la agenda pública la problematización de la temática.

- Un ciclo de cine y video documental (La rurbanidad al palo), participación en jornadas de divulgación y otros eventos públicos, y la convicción de que el trabajo académico trasciende la mera coloquización de lo real sembraron en la sensibilidad pública algunas semillas para que el pensamiento social no haga caso omiso de esas emergencias.

\section{A modo de cierre}

En toda comunidad ser y sentirse miembro depende de diversos factores. En la sociedad moderna algunos se vinculan al derecho y otros a los hechos. Los primeros tienen garantías en la ley y los segundos reposan en las concepciones y en las prácticas,

15 Carreros. Relatos desde el rebusque (material en DVD de veinte minutos de duración) testimonia la experiencia rurbana de los carreros. Actores sociales que residiendo en la ciudad sin embargo comparten saberes, valores y prácticas de vida asociadas con lo rural, como lo puede ser su actividad acompañada de carros y caballos. La meta de la propuesta es buscar que el conocimiento y la discusión social sobre el sector y sus experiencias de rebusque merezca la comprensión y el respeto de la ciudadanía, con la finalidad de lograr una comunidad mucho más inclusiva e integrada y sensible a las problemáticas sociales. La actividad principal de esta propuesta es trabajar en la sensibilización pública y apoyo escolar por medio de talleres que utilicen este material audiovisual. 
por eso no dependen de normas ni requisitos sino de las continuas operaciones sociales que en las tolerancias e intolerancias cultivan la integración o exclusión.

El caso que nos ocupa permite discutir esas operaciones. Pone en relieve la necesidad de que los instrumentos existentes -de la educación, de la investigación y de la participación ciudadana- actúen para que el formato final del orden se configure desde la integración, desde la suma y nunca desde la expulsión.

En el campo comunicacional la pregunta sobre los haceres y sus derivas éticas y profesionales ocupa poco lugar. Las "industrias culturales" a diario, sin embargo, ponen a prueba cuánto de madurez la sociedad ha conseguido edificar y sostener para que ante casos no deseables prime el buen censo y se opaque la estigmatización.

Esos problemas no están afuera ni empiezan cuando la luz del micrófono indica que está listo para amplificar. El trabajo es permanente y de igual signo deberá ser la convicción que lo estimule. Si nuestro campo está atento a las formaciones que ofrece, a las prácticas que resultan y al conocimiento que se constituye en estratégico para abonar una construcción más amplia de la sociedad, habremos hecho un aporte. Seguramente pequeño, pero inmensamente necesario y multiplicador.

\section{Bibliografía}

Abatedaga, N. (comp.) (2008). Сomunicación: Epistemología y metodologías para planificar por consensos. Córdoba: Brujas.

AFSCA (Autoridad Federal de Servicios de Comunicación Audiovisual) (2009). Ley de Servicios de Comunicación Audiovisual 26.522. <http:// www.afsca.gob.ar/web/indice-dela-ley.php>.

Cátedra Unesco de Comunicación para el Desarrollo (8-10 de setiembre del 2008). "Memorias del seminario Políticas de Comunicación y Cultura en Colombia", organizado por la Facultad de Comunicación y Lenguaje de la Pontificia Universidad Javeriana - Bogotá. Inédito.

Clayss (Centro Latinoamericano de Aprendizaje y Servicios Solidarios). $<$ http://www.clayss.org.ar/>.

Cimadevilla, Gustavo (2010). "La cuestión rurbana: Apuntes para una entrada comunicacional". Revista Brasileira de Comunicação. Vol. 33, núm. 2. São Paulo.

Cimadevilla, G. y E. Carniglia (coords.) (2009). Relatos sobre la rurbanidad. Río Cuarto: UNRC.

Cimadevilla, G.; Demarchi, P. y S. Galimberti (2010). "La rurbanidad ausente: Visibilidades e invisibilidades mediáticas". Revista Signo y Pensamiento 58. Bogotá: Pontificia Universidad Javeriana. 
Gramsci, Antonio (2000). Los intelectuales y la organización de la cultura. 6. ${ }^{a}$ edición. Buenos Aires: Nueva Visión.

Grillo, Mabel (2011). El negro argentino: nación, raza y clase en épocas de la globalización. Río Cuarto: UNRC.

Heler, M. (2004). Ciencia incierta. La producción social del conocimiento. Buenos Aires: Biblos.

Locke, J. (2011). “Ensayo sobre la tolerancia". Selección de textos. Traducción, introducción y notas de Blanca Rodríguez López y Diego A. Fernández Peychaux. Madrid: Biblioteca Nueva.

Martín Barbero, J. (2005). “Transdisciplinariedad: Notas para un mapa de sus encrucijadas cognitivas y sus conflictos culturales", en Jaramillo Jiménez, J. (comp.). Cultura, identidades y saberes fronterizos. Bogotá: Universidad Nacional de Colombia. (1997). "No podemos renunciar a un proyecto de país" en Revista
Signo y Pensamiento. Nro. 31. PUJBogotá.

(1987). De los medios a las mediaciones. México, D. F.: Gustavo Gili.

ONU (1948). Declaración Universal de los Derechos Humanos. <http://www. un.org/es/documents/udhr/>.

Romero, José L. (2009). La ciudad occidental. Buenos Aires: Siglo XXI Editores.

UNRC-Municipalidad de Río Cuarto (2010). Carreros. Relatos desde el rebusque. Video. <http://www.youtube.com/watch?v=yNSYd6hLZC8>.

Vassallo de Lopes, I. y R. Fuentes Navarro (2005). Comunicación. Campo y objeto de estudio. Jalisco: Iteso.

Wallerstein, I. (2003). Impensar las ciencias sociales. México, D. F.: Siglo XXI Editores.

Wolf, Mauro (1987). La investigación de la comunicación de masas. Barcelona: Paidós. 